\title{
EFEMERIDADE E NOMADISMO: UM OLHAR ENTRE DESIGN DE MODA E ARQUITETURA
}

Marcus Vinicius Pereira, mestrando

Universidade Anhembi Morumbi

Cristiane Mesquita, Dra

Universidade Anhembi Morumbi

Resumo: Este artigo objetiva comunicar uma pesquisa de mestrado que se encontra em fase de desenvolvimento, propondo-se a tratar de conceitos que modificaram a relação de tempo e espaço na sociedade contemporânea, possíveis de serem identificados nos campos do design de moda e da arquitetura. Para tanto, são conceituados autores e estudos de caso que tratam de tais temáticas. No primeiro momento da pesquisa contextualizam-se as mudanças que aconteceram no contemporâneo que modificaram e incorporaram novos modos de viver ao cotidiano. Esses novos hábitos e a influência da tecnologia, aproximam conceitos da arquitetura e do design de moda, como o habitar e o vestir, possibilitando a criação de vestíveis que se tornam espaço e de espaços efêmeros. Estas questões podem ser observadas na coleção Afterwords do designer Hussein Chalayan e na obra arquitetônica Blur Building do estúdio Diller Scofidio abordados neste trabalho.

Palavras-chave: design de moda, arquitetura, efemeridade, nomadismo.

\begin{abstract}
This article has the objective to communicate a mastership research that currently in a devolepment process, proposing to deal with concepts that have changed the relationship of time and space in contemporary society, these concepts can identified in the fields of fashion design and architectureln order to do so, renowed authors and case studies are mentioned in the theme. At first, the research contextualizes the changes that have occurred in the contemporary times that have modified and incorporated new ways of living in the everyday life. These new habits and the influence of technology have brought closer to us concepts of architecture and fashion design, like the inhabit and the garments, making it possible the creation of wearables that become space and ephemeral spaces. This questions can be noticed in the collection Afterwords from the designer Hussein Chalayan and in the architecture work Blur Building from the studio Diller Scofidio that are addressed in this paper.
\end{abstract}

Keywords: fashion design, architecture, ephemerality, nomadism. 


\section{INTRODUÇÃO}

A sociedade contemporânea é marcada por uma série de mudanças que ocorrem após a Segunda Guerra Mundial, tais como novos modos de produção e linguagens. Áreas como Design de Moda e Arquitetura tornam-se mais experimentais e propensas aos diálogos.

Os conceitos de corpo e de espaço associam-se a conceitos como mobilidade e efemeridade, à medida que as formas de interação social se modificam e os avanços tecnológicos aceleram os modos de comunicação.

Este artigo apresenta uma síntese da abordagem que vem sendo realizada em pesquisa de Mestrado ${ }^{1}$. A pesquisa é de natureza qualitativa e de caráter exploratório, com dados levantados por meio de referências bibliográficas, a respeito do contexto da sociedade contemporânea, em conjunto com uma pesquisa iconográfica, com exemplos de projetos de arquitetura e coleções de design de moda que trabalham o conceito de efemeridade e nomadismo.

Nesse contexto, o projeto Blur Building, desenvolvido pelo estúdio de arquitetura Diller Scofidio e a coleção Afterwords, de autoria do designer Hussein Chalayan são emblemáticos para as discussões que a pesquisa pretende travar.

\section{DESENVOLVIMENTO}

\subsection{ANOS VERTIGINOS}

No contemporâneo, é possível observar uma aceleração que reflete diretamente nos modos de viver da sociedade, modificando diretamente seus modos de trabalhar, falar, sentir, agir, enfim, suas subjetividades, como afirma Rolnik (1989). Mesquita (2004), completa que a subjetividade está em constante modificação, já que a sociedade/indivíduo é atravessado o tempo todo por diversos vetores em cada uma de suas experiências de vida, sua existência.

\footnotetext{
"A subjetividade está em circulação nos conjuntos sociais de diferentes tamanhos: ela é essencialmente social, e assumida e vivida por indivíduos em suas existências particulares. O indivíduo está na encruzilhada de múltiplos componentes da subjetividade". (MESQUITA, 2004, p.15)
}

A partir da segunda metade do século XIX, o mundo se transformou por conta de uma série de novos processos de subjetivação. Cardoso (2008) afirma que essas mudanças foram tão importantes economicamente que podem ser comparadas com o desenvolvimento da agricultura na pré-história, durante o período neolítico, considerado um passo decisivo para o desenvolvimento humano.

Essas transformações foram se acelerando e ganhando proporções colossais. Para Sevcenko (2001), essas alterações modificaram a própria estrutura da sociedade social, econômica e política - principalmente por conta do grande número de indústrias que foram surgindo. Esse processo de industrialização pode ser entendido

1 Este artigo é parte da pesquisa de Mestrado "Design de Moda e Arquitetura: efemeridade e nomadismo entre corpos e espaços", em curso no PPGDesign da Universidade Anhembi Morumbi, de minha autoria sob orientação da Prof. Dr.a Cristiane Mesquita. 
como o momento em que a agricultura e o comércio foram substituídos pela indústria, que passou a ser à base da economia.

Segundo Cardoso (2008), a industrialização gerou outro processo que marca esse período de modificações, a urbanização. Com a crise na agricultura, a população rural se deslocou para as cidades em busca de emprego e melhores condições de vida. Esse movimento causou uma série de problemas sociais, visto que essas cidades não estavam preparadas para receber esse grande número de migrantes vindos do campo, dando inicio às primeiras metrópoles.

Em 1870, com a Revolução Científico Tecnológica, novos campos industriais foram gerados, como as indústrias elétricas, químicas e petrolíferas. Este fato promoveu movimentos operários que contestavam o tradicional sistema politico vigente por meio de associações, sindicatos e partidos. Para Sevcenko (2001) tais movimentos aumentaram o poder de contestação da classe operária, se opondo aos valores da sociedade burguesa, mudando as condições de vida das pessoas e reorganizando as rotinas do seu cotidiano.

Essas mudanças sociopolítico-econômicas passaram a dominar os modos de produção, que se adaptaram a máquinas cada vez mais modernas e aceleradas, como lembra Sevcenko (2001). Tais acelerações são impulsionadas principalmente pela preeminência das máquinas e das engenharias de fluxos (sistemas de fornecimento de água/esgoto, energia elétrica, gás, telefone, transportes) que, em ritmo acelerado, mudam os valores da sociedade.

Outro processo fundamental para a aceleração frenética que ocorreu foi a globalização, impulsionada pelos novos meios de transporte, como transatlânticos, carros, caminhões, motocicletas, trens expressos e aviões, trazendo muito mais velocidade para o cotidiano dessa sociedade. Os novos meios de comunicação, como o telégrafo, o rádio, a fotografia e o cinema, também contribuíram significativamente nesta modificação da velocidade.

\footnotetext{
O século 19 foi palco de uma revolução nos meios de transportes e de comunicação que só parece menos fantástica e comparação com a sua aceleração continua posterior. A introdução das estradas de ferro, da navegação a vapor, do telégrafo, da fotografia e de outras inovações (...) alterou inteiramente as perspectivas para a distribuição de mercadorias e de informações, estabelecendo os alicerces do processo de globalização que gera tanta discussão nos dias de hoje. (CARDOSO, 2008, p.43)
}

O desenvolvimento de várias inovações dos setores de transportes e comunicação permitiu um intercâmbio global mais rápido. Com isso, a necessidade de ampliar seus mercados levou as nações, aos poucos, a começarem a se abrir para produtos de outros países.

Segundo Santos "a instantaneidade da informação globalizada aproxima os lugares, torna possível uma tomada de conhecimento imediata de acontecimentos simultâneos e cria, entre lugares e acontecimentos, uma relação unitária na escala do mundo" (SANTOS, 1996, p. 49).

A velocidade das informações, por conta da globalização, alterou significativamente a noção de espaço e de tempo da sociedade, fazendo com que o novo seja algo necessário e constante. Lipovetsky completa ainda que "a mudança não é mais um fenômeno acidental, raro, fortuito, tornou-se uma regra permanente" 
(LIPOVETSKY, 1989, p.30). O indivíduo contemporâneo que vive nessa "velocidade de informações" precisa se tornar muito mais flexível, visto que a efemeridade é um vetor dos processos de subjetivação no contemporâneo. Neste contexto, Pelbart enfatiza mudanças consideráveis na percepção entre as relações entre tempo e espaço no contemporâneo:

Já não navegamos num rio do tempo, que vai de uma origem a um fim, mas fluímos num redemoinho turbulento, indeterminado, caótico. A direção do tempo se dilui a olhos vistos. Também a espessura do tempo se evapora, nem mais parecemos habitar o tempo, e sim a velocidade instantânea, ou a fosforescência das imagens, ou os bits de informação. (PELBART, 2011, p.76)

Após a Segunda Guerra Mundial, essa série de transformações se acelera ainda mais, configuração demarcada conceitualmente por alguns autores como pósmodernidade (LYOTARD, 1986). Surgem novos modos de produção e de consumo, promovendo com que áreas como do design de moda e da arquitetura absorvam essa velocidade. A partir daqui abordaremos mais especificamente dois setores nesse contexto, no que concerne ao design de moda e a arquitetura.

\subsection{DESIGN DE MODA E ARQUITETURA: OLHARES SOBRE TEMPO E ESPAÇO}

Segundo Lipovetsky (1989) somente a partir do século XIV, no final da Idade Média, a moda se consolida como sistema, fazendo com que a renovação das formas instaure-se como regra absoluta. Neste primeiro momento - em torno de cinco séculos - a moda vive seu momento artesanal e aristocrático.

É nesse momento, que acontece o nascimento da Haute-Couture ${ }^{2}$. Em termos de temporalidade, é possível pensar que as variações do vestuário se davam de modo mais lento, sendo a história da moda desde então, apresentada a partir do estilo especifico dos grandes costureiros ou em suas variações por décadas como completa. (MESQUITA, 2004)

Após a Segunda Guerra Mundial, a sociedade que já vinha desde o século XIX acelerada, ao ritmo das grandes máquinas, se acelera ainda mais, fazendo com que os grandes mestres da costura, incorporem toda essa velocidade em suas criações e através de seus modelos tornem o cotidiano dessa sociedade mais prático, nascendo o chamado prêt-à-porter ${ }^{3}$.

Para Lipovetsky (1989) na Alta Costura existia uma certa semelhança de gostos, e com o nascimento desse novo sistema, "já não há uma moda; há modas" (LIPOVETSKY, 1989, p. 124). Neste momento é possível reconhecer que os modos de produção no setor de vestuário, passam a funcionar na lógica de produção do design, sendo possível a partir de então, entender o setor como design de moda.

\footnotetext{
${ }^{2}$ O termo Haute-Couture em francês que significa Alta Costura. "Forma de funcionamento caracterizada também pela exclusividade das peças, matéria-prima luxuosa e técnicas artesanais”. (MESQUITA, 2004, p.28).

${ }^{3} \mathrm{O}$ termo em francês prêt-à-porter foi uma apropriação "do inglês ready to wear - que significa "pronto para usar" - cunhada pelos empresários franceses Jean-Claude Weil e Albert Lempereur, em 1948" (MESQUITA, 2004, p.28).
} 
Se no advento do prêt-à-porter foi possível observar no campo do design de moda, os reflexos das mudanças nos modos de subjetivação de uma sociedade, por conta de uma aceleração nos modos de viver, no contemporâneo pode-se notar que essa aceleração, alinhada com a velocidade de informações chega a um nível jamais imaginado, com a chegada do fast fashion ${ }^{4}$.

Segundo Cietta (2010) a maioria das grandes empresas do setor o adotou esse sistema, por volta do fim década de 1990, numa tentativa de corresponder aos anseios dos consumidores cada vez mais exigentes e sedentos por novidades.

Ao longo do século $X X$, o setor da arquitetura também vem se modificando vertiginosamente - desde sistemas construtivos até a forma de se projetar. Vitrúvio, autor romano responsável pelo mais antigo tratado a respeito de arquitetura que chegou à atualidade, pontua que a arquitetura deveria ser pautada por três princípios básicos.

O primeiro destes princípios é o de firmitas que se refere à estabilidade e solidez, ao caráter construtivo da arquitetura, abrangendo questões como resistência e, principalmente, permanência. O segundo é o de utilitas, que se origina da comodidade e, ao longo da história, foi associado à função e ao utilitarismo, unindo-se na funcionalidade. $\mathrm{O}$ ultimo deles é o de venustas, que se encontra associado à beleza e apreciação estética.

Neste contexto, em termos de relação com o espaço, vale ressaltar alguns momentos distintos que ilustram modos diversos na produção arquitetônica. No período da antiguidade clássica - aproximadamente do século VIII a.C. ao século V d.C. -, é possível observar projetos onde nota-se presente os três princípios abordados por Vitrúvio, mas em especial o de firmitas, visto que eram obras feitas para durar eternamente, como no caso do Parthenon, templo grego dedicado à deusa Atena construído no século V a.C., feita para durar para "sempre".

Esses três conceitos trabalhados por Vitrúvio no período da antiguidade clássica, posteriormente são retomados no Renascimento Italiano, durante os séculos XV e XVI por Leon Batista Alberti e Andréa Palladio em seus tratados de arquitetura como afirma Dziura (2006).

Vários outros tratados foram escritos, se tornando uma importante fonte da difusão da ciência sobre a arte de projetar arquitetura como afirma Ramos (2011). Esses tratados eram pautados como fontes incontestáveis de "como se fazer arquitetura" amparadas na arquitetura clássica, onde toda e qualquer arquitetura que não se enquadrassem nesses princípios não eram de qualidade ou não teriam relevância.

Posteriormente aos tratados escritos no renascimento, podemos ver reflexos já no século XX com os textos publicados por Le Corbusier, grande nome do movimento modernista, que acreditava que a arquitetura poderia criar uma nova sociedade.

Le Corbusier em seu livro Vers une architecture de 1923 discute cinco pontos chaves para uma nova arquitetura ${ }^{5}$. Podemos observar esses cinco pontos pautados por Le Corbusier em uma casa projetada por ele entre 1928-31 em Poissy, na França. A obra batizada de Villa Savoye "é uma caixa de concreto branca elevada, vazada

\footnotetext{
${ }^{4} \mathrm{Em}$ termos gerais, trata-se de um sucesso entre os sistemas da moda na atualidade. (CIETTA, 2010)

${ }^{5}$ Os cinco pontos pautados por Le Corbusier da 'nova arquitetura' são: "suportes livres no térreo (pilotis), o terraço jardim, a planta livre, a janela em fita e a fachada de composição livre". (NUTTGENS, 2015, p.268)
} 
horizontalmente e verticalmente" (NUTTGENS, 2015, p.268), construída para ser a residência de fim de semana.

Um reflexo que podemos perceber da industrialização que ocorria durante esse período na arquitetura, é quando Le Corbusier a seguinte comparação: "a casa é uma máquina de morar" (NUTTGENS, 2015, p.270), trabalhando o conceito de que a forma deve seguir a função.

Já nos anos 1960, um grupo inglês, formado pelos arquitetos recém graduados Peter Cook, Warren Chalk, Michael Webb, David Greene, Ron Herron e Dennis Crompton, denominado de Archigram, incorporaram a ideia de fluxo e comunicação a arquitetura e iniciaram a publicação de uma revista ilustrada de caráter contestatório e provocativo, que também levava o nome de Archigram, mistura das palavras em inglês arquitetura e telegrama como afirma Silva (2004).

Segundo Rolim (2009) o Archigram criou projetos inovadores, inspirados na tecnologia como forma de expressão, como a vida em cápsulas e casulos, estruturas orgânicas, infláveis, extensíveis e cidades instantâneas, revolucionando "o conceito de mobiliário, casa, cidade, promovendo a síntese entre corpo, arquitetura portátil, mobilidade, arte, utopia e ativismo" (ROLIM, 2009, p. 48).

Na proposta para o projeto Walking City de 1964, o grupo trabalha o conceito de uma cidade andante, de "uma arquitetura sem fundações e sem raízes, constituída por imensos containers com pernas tubulares que se deslocam pelo solo e pelas águas em constante movimento". (SILVA, 2004). Archigram aproximou em muitas de suas obras conceitos como do nomadismo, combinados a hiper-tecnologia como afirma Silva (2004). Apesar desses projetos não serem realizados concretamente, serviram de repertório para diversas outras tendências, como o estilo conhecido como high-tech.

Inúmeros vetores que formam a subjetividade contemporânea - econômicos, políticos, culturais, sociais - e se encontram em constante cruzamento, impulsionando os campos do design de moda e da arquitetura a se modificar, adaptando-se a novas maneiras de viver e fazendo com que ideias mudem, estruturas se diluam e novos conceitos se desenvolvam. No item a seguir, observaremos nos estudos de caso escolhidos, reflexos dos conceitos de efemeridade e nomadismo.

\subsection{HUSSEIN CHALAYAN E DILLER SCOFIDIO}

No contexto destes diálogos, no campo do design de moda, vale destacar o designer cipriota Hussein Chalayan e a coleção outono/inverno do ano de 2000, batizada de Afterwords, onde designer problematiza a ideia de ter de fugir de uma casa em tempos de conflitos, como afirma Vrencoska (2009). 


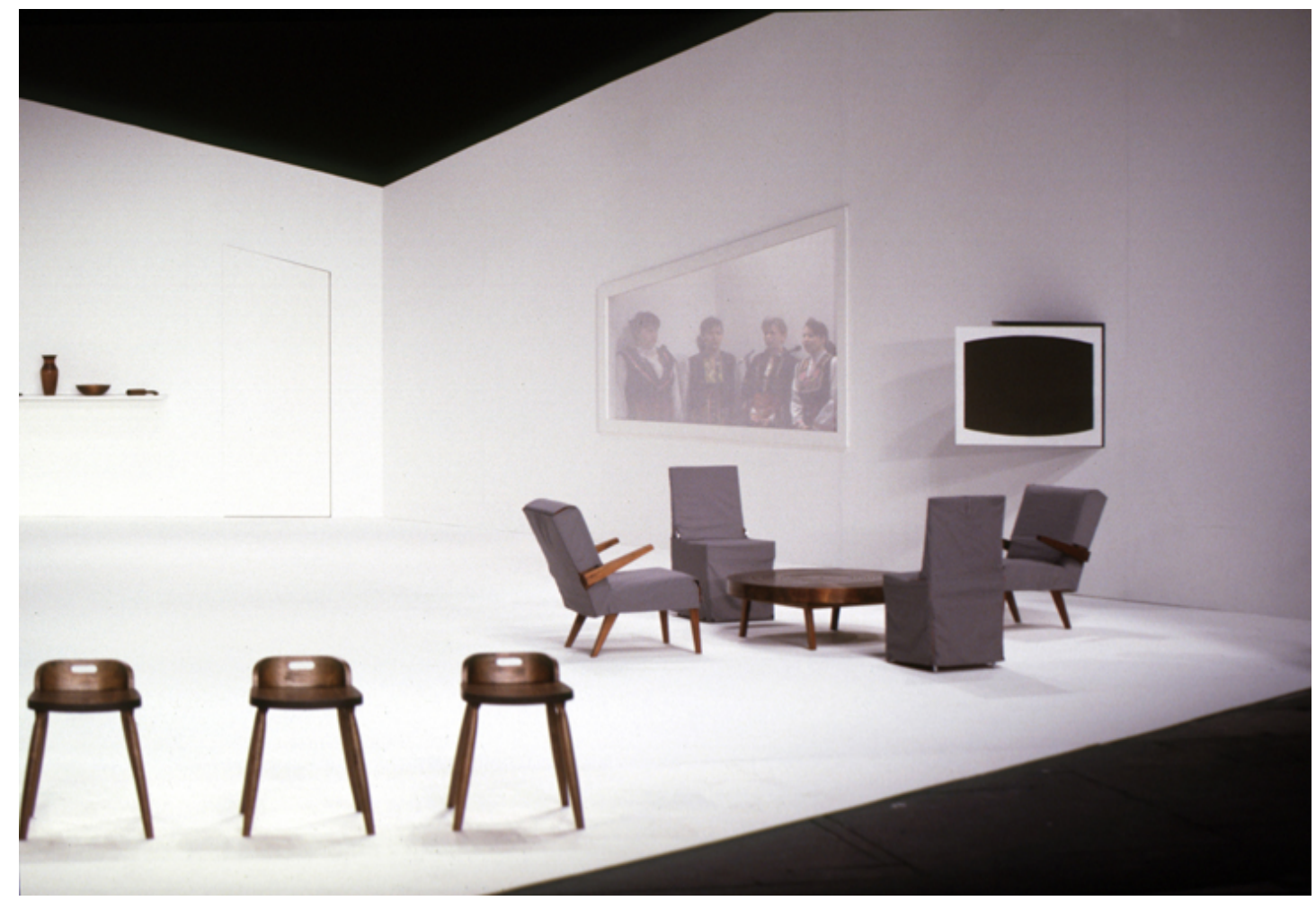

Figura 1 - Coleção Afterwords.

Fonte: <http://chalayan.com/afterwords/> - Acesso em: 20 abr. 2015

Essa concepção tem como inspiração a crise em Kosovo, em 1999, dialogando com o que vinha acontecendo na llha de Chipre, disputada por duas comunidades distintas. Na limpeza étnica, em 1974, Chipre foi dividido em duas partes: dominação grega no Sul e dominação turca no Norte.

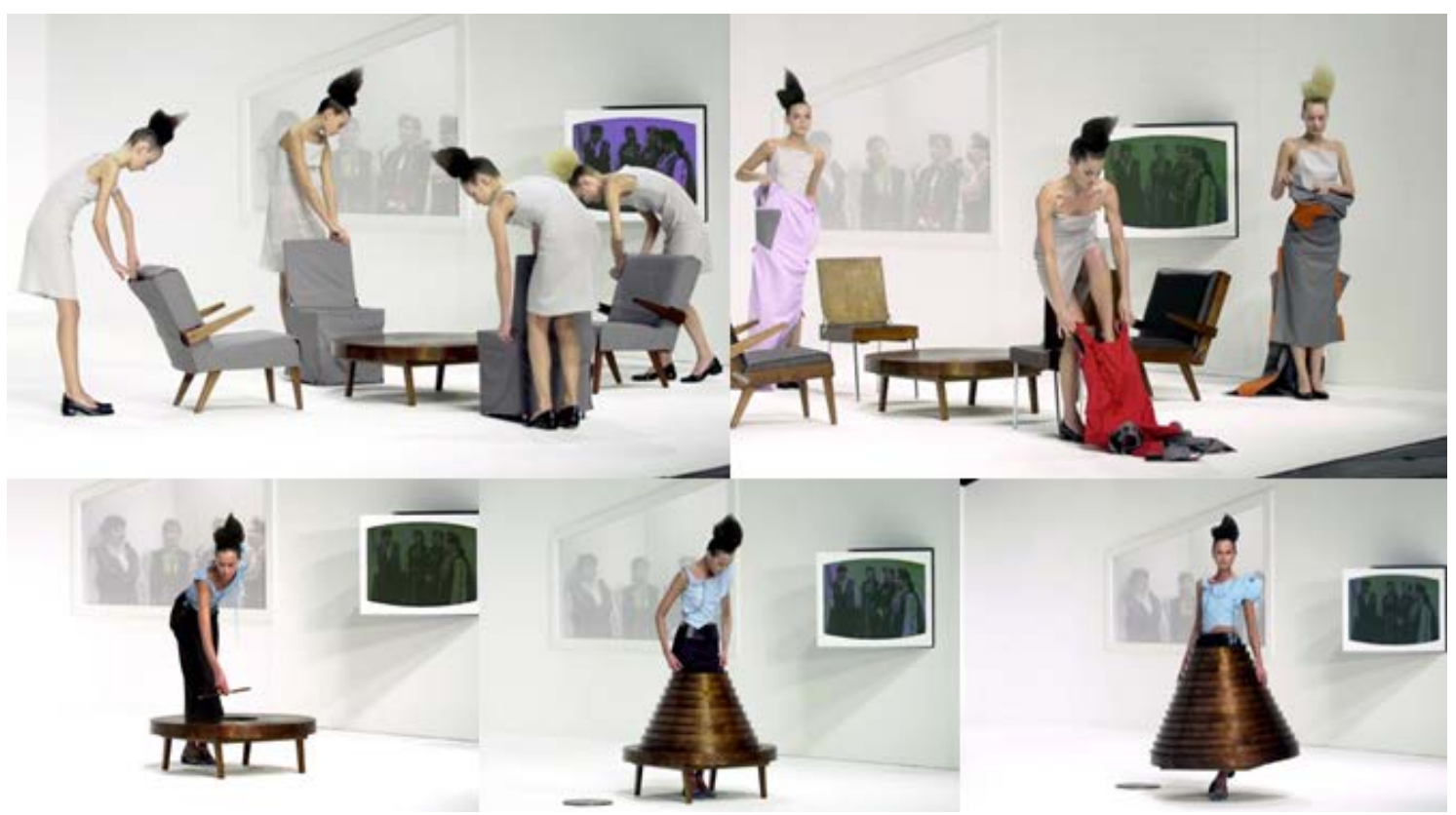

Figura 2 - Coleção Afterwords.

Fonte: <http://chalayan.com/afterwords/> - Acesso em: 20 abr. 2015 
Segundo Gouthier "a performance faz alusão à maneira como os turco-cipriotas foram submetidos a lavagens étnicas e obrigados a deixarem as suas casas" (GOUTHIER, 2013, p. 19). Chalayan cria uma sala de estar onde as roupas e mobiliários se confundem, problematizando como indivíduos que, diante da guerra, precisam partir de suas casas e levar consigo seus pertences - por vezes, obrigados a deixar para trás muitos utensílios, por não terem como transportá-los como afirma Vrencoska (2009).

No caso da arquitetura, nosso dialogo enfoca a arquitetura fluida construída no meio do lago Neuchâtel, na Suíça, pelo estúdio de design Diller Scofidio ${ }^{6}$ para a Expo de 2002. A estrutura, batizada de Blur Building, constituía uma "nuvem", fabricada pela água do próprio lago. A água, filtrada e pressurizada era lançada por mais de 35 mil aspersores espalhados pela estrutura metálica, que contava com 90 metros de largura, 60 metros de profundidade e 20 metros de altura, como afirma Neves (2011).

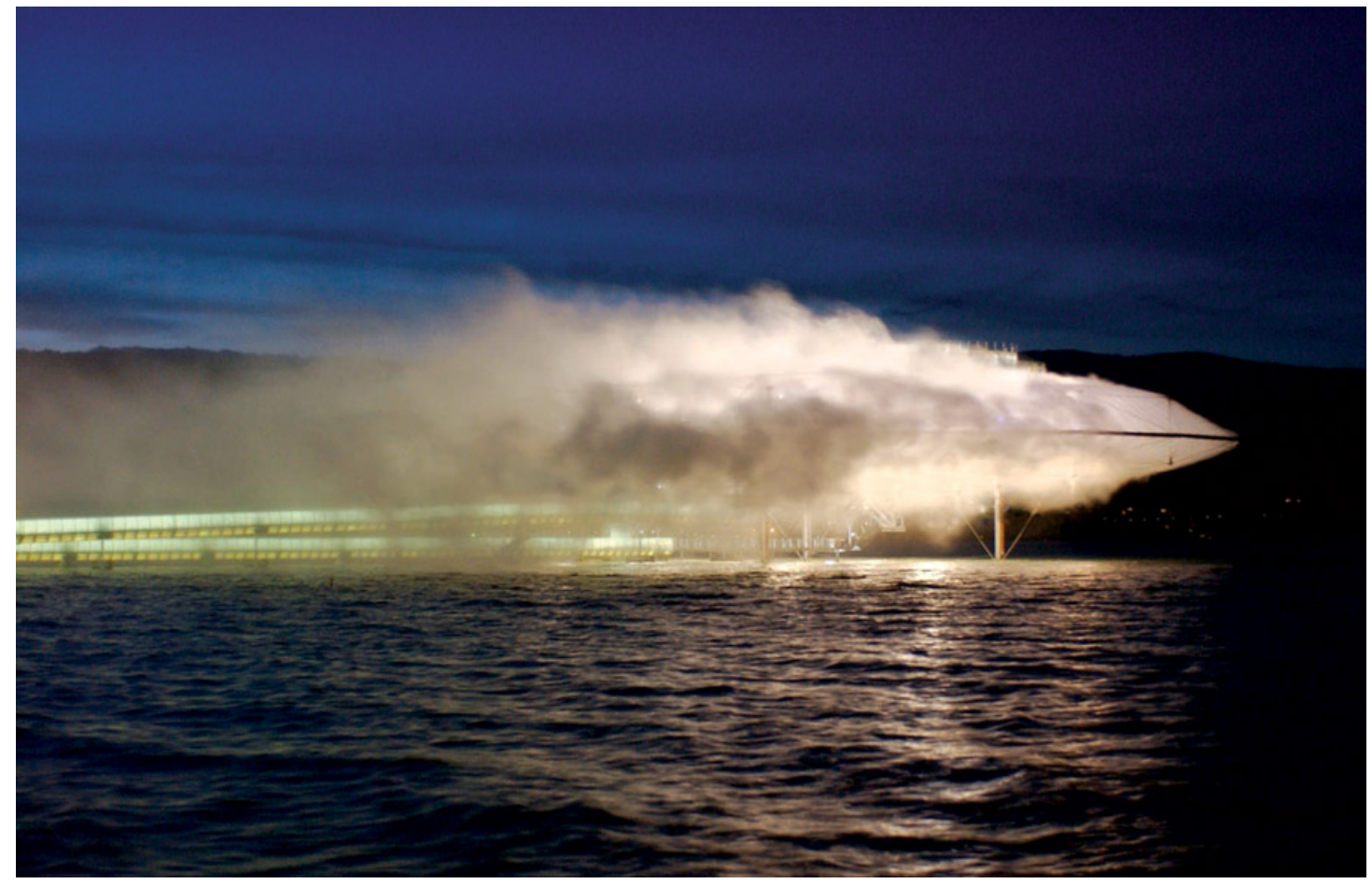

Figura 3 - Blur Building.

Fonte: <http://www.dsrny.com/\#/projects/blur-building> - Acesso em: 20 abr. 2015

Segundo Diller (2005), penetrar na nuvem é como penetrar num espaço, andando pelo interior de um meio habitável e disforme que não tem limite, cor, profundidade, escala, massa, superfície ou dimensão. O projeto foi um espetáculo para ser sentido e não contemplado. Ele obriga a vivência pelo movimento, pelo caminhar sem rumo no espaço, e pode proporcionar ao corpo a experiência de vagar pela névoa, perdendo a noção de altura, profundidade e largura, experienciando a sensação de habitar o vazio. Cada indivíduo tem uma experiência única, já que a estrutura podia ser apenas sentida, fazendo o "edifício" envolvê-lo, criando um edifício/vestível.

\footnotetext{
${ }^{6}$ Atualmente o nome do estúdio Diller Scofidio mudou para Diller Scofidio+Renfro, por conta da entrada do novo sócio Charles Renfro, em 2004. Contudo, neste trabalho optou-se por utilizar o antigo nome visto que o objeto de estudo que será analisado foi realizado durante este período.
} 


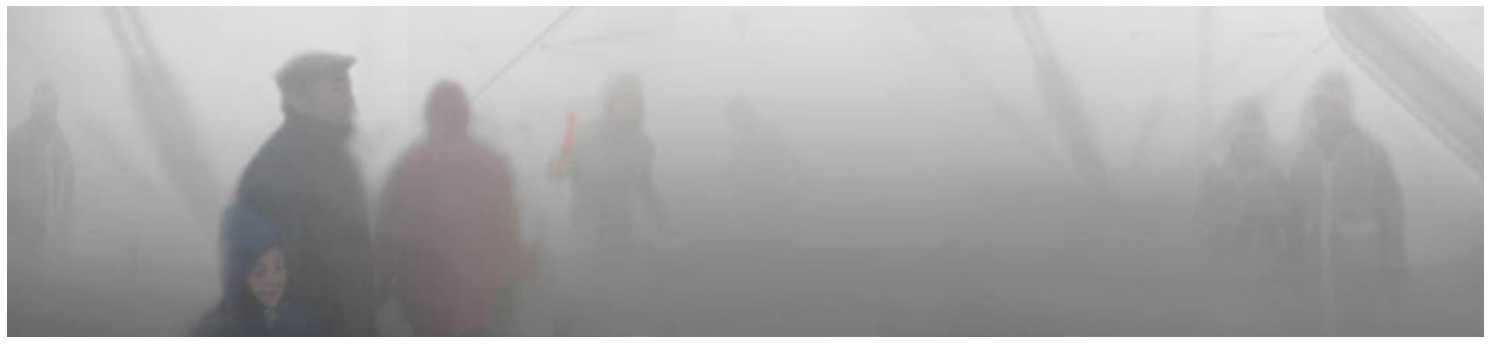

Figura 4 - No interior da estrutura.

Fonte: <http://www.archidose.org/writings/blur.htmlbuilding> - Acesso em: 20 abr. 2015

É possível considerar que o design de Hussein Chalayan e a arquitetura de Diller Scofidio explicitam com esses trabalhos, a efemeridade e a transitoriedade que atravessam os modos de vida no contemporâneo. Chalayan apresenta uma roupa que, inicialmente, é um mobiliário que localiza se no espaço e carrega em si a potência de tornar-se um vestível. Na perspectiva do espaço o estúdio Diller Scofidio apresenta um espaço onde os corpos são envolvidos por um espaço efêmero, ou seja, que carrega em si a potência de dissolver-se em instantes.

\section{CONSIDERAÇÕES FINAIS}

Esta pesquisa encontra-se em fase de desenvolvimento de resultados. Neste artigo, vale considerar que o contexto e os trabalhos apresentados colaboram para discussões em torno de importantes conceitos que permeiam a sociedade contemporânea, fazendo interfaces entre os campos do Design de Moda, a Arquitetura e a Filosofia.

Nesse sentido, produções advindas dos campos do Design de Moda e da Arquitetura tais como os trabalhos mencionados são relevantes para discussões em torno desses cruzamentos bem como de diálogos entre os campos mencionados.

Chalayan toca em diversos pontos da arquitetura, desde aos materiais usados no desenvolvimento de sua coleção, até mesmo quando expressa um pensamento projetual, que é comum entra as áreas.

Diller Scofidio coloca em pauta questões relativas ao vestir e ao corpo ao criar uma obra cuja ênfase está no involucro do corpo. Desta forma explícita um dos pilares do sistema da moda, pois não foca no espaço eternizado do pensamento clássico da arquitetura, mas sim enfatiza a efemeridade, ou seja, aquilo que varia no tempo.

\section{REFERÊNCIAS}

CARDOSO, Rafael. Uma introdução à história do design. 3. ed. São Paulo: Edgard Blücher, 2008.

CIETTA, Enrico. A revolução do fast fashion. Estratégias e modelos organizativos para competir nas indústrias híbridas. São Paulo: Estação das Letras e Cores, 2010.

DILLER, Elizabeth. Blur Building - Yverdon-les-Bains, Swiss Expo 02.Disponível em: <http://www.bbr.bund.de/english/publications/download/Diller_15_bis_17.pdf> Acesso em: jun. 2006. 
DZIURA, Giselle L. Três Tratadistas Da Arquitetura E A Ênfase No Uso Do Espaço. Da Vinci, v. 3, n. 1, p. 19-36. Curitiba, 2006.Disponível em:

<http://www.up.edu.br/davinci/3/303_tres_tratadistas_da_arquitetura.pdf> Acesso em: nov. 2015

GOUTHIER, Priscila. Interatividade: Moda, Corpo e Tecnologia. Achiote (Belo Horizonte) , v. 1, n. 1, p. 1-22, 2013. Disponível em:

<http://www.fumec.br/revistas/achiote/article/view/1644/1040>Acesso em: jun. 2015.

LIPOVESTKY, Gilles. 0 império do efêmero - uma moda e seu destino nas sociedades modernas. São Paulo: Companhia das Letras, 1989.

LYOTARD, Jean François. O pós-moderno. Tradução Ricardo Correia Barbosa. Rio de Janeiro: J. Olympio, 1986.

MESQUITA, Cristiane. Moda contemporânea: quatro ou cinco conexões possíveis. São Paulo: Editora Anhembi Morumbi, 2010.

NEVES, Juliana D. Sobre projetos para todos os sentidos: Contribuições da arquitetura para o desenvolvimento de projetos dirigidos aos demais sentidos além da visão. 2011. 146 f. Dissertação (mestrado) - Pontifícia Universidade Católica do Rio de Janeiro, Departamento de Artes \& Design. Disponível na internet por http em:

$<$ http://www.maxwell.vrac.puc-

rio.br/Busca_etds.php?strSecao=resultado\&nrSeq=19246@1> Acesso em 03 jun.2015

NUTTGENS, Patrick. A História da Arquitetura. Tradução Luiz Queiroz e Denise de Alcantara Pereira. 2a ed. Rio de Janeiro: LTC, 2015.

PELBART, Peter Pál. Desvios do tempo. In: Cristine Mesquita; Rosane Preciosa. (Org.). Moda em ziguezague: Interfaces e Expansões. São Paulo: Estação das Letras e Cores, 2011, p. 75-86.

RAMOS, Fernando G. V. Os tratados do século XX: edições especiais. 2011. In Revista Eletrônica de Arquitetura e Urbanismo. Universidade São Judas Tadeu, São Paulo, 2011. p. 55-74. Disponível na internet por http em: <

http://www.usjt.br/arq.urb/numero_05/arqurb5_07_artigo_fernando_vazquez.pdf> Acesso em 09 abr. 2016.

ROLIM, Marion Velasco. Wearable<\#>Home, A Vestimenta como Lugar. 2009. $130 \mathrm{f.}$ Dissertação (mestrado) - Universidade Anhembi Morumbi, Curso de Design. Disponível na internet por http em: <http://www.anhembi.br/mestradodesign/pdfs/marion.pdf> Acesso em 09 fev. 2012.

ROLNIK, Suely. Cartografia sentimental: transformações contemporâneas do desejo. São Paulo: Estação Liberdade, 1989.

SANTOS, Milton. Técnica, espaço, tempo: globalização e meio técnico-científicoinformacional. 2aed. São Paulo: Editora Hucitec, 1996.

SEVCENKO, Nicolau. A Corrida para o Século XXI. No loop da montanha-russa. São Paulo: Cia. das Letras, 2001.

SILVA, Marcos S. K. Redescobrindo a arquitetura do Archigram. Arquitextos, São Paulo, ano 04, n. 048.05, Vitruvius, maio 2004. Disponível na internet por http em: 
<http://www.vitruvius.com.br/revistas/read/arquitextos/04.048/585> Acesso em 14 abr. 2015.

VITRUVIUS, Pollio. Tratado de Arquitetura. Trad. M. Justino Maciel. São Paulo: Martins Fontes, 2007.

VRENCOSKA, G. Political statements in conceptual fashion: The voice of national sentiments as a self-reference in the ready-to-wear collections of Alexander

McQueen and Hussein Chalayan. Annual Review n.2, European University: Republic of Macedonia, 2009. Disponível na internet por http em:

$<$ https://www.academia.edu/396286/Political_statements_in_Conceptual_Fashion_Th e_voice_of_national_sentiments_as_a_self-reference_in_the_Ready-To-

Wear_collections_of_Alexander_McQueen_and_Hussein_Chalayan> Acesso em 14 abr. 2015. 